\title{
Regulation of gene transcription of B lymphoma Mo-MLV insertion region 1 homolog (Review)
}

\author{
MEIZHEN ZHOU, QICHAO XU, DEQIANG HUANG and LINGYU LUO \\ Department of Gastroenterology, Research Institute of Digestive Diseases, \\ The First Affiliated Hospital of Nanchang University, Nanchang, Jiangxi 330006, P.R. China
}

Received June 19, 2020; Accepted February 19, 2021

DOI: $10.3892 /$ br.2021.1428

\begin{abstract}
B lymphoma Mo-MLV insertion region 1 homolog (Bmi-1) is a core protein component of the polycomb repressive complex 1 that inhibits cell senescence and maintains the self-renewal ability of stem cells via downregulation of p16Ink4a and p19Arf expression. Bmi-1 serves an important role in hematopoietic stem cell maintenance and neurodevelopment during embryonic development, and it has been shown to enhance tumorigenesis by promoting cancer stem cell self-renewal and epithelial to mesenchymal transition. Emerging evidence suggests that $B m i-1$ overexpression is closely related to the development and progression of various types of cancer, and that downregulation of Bmi-1 expression can inhibit the proliferation, invasion and metastasis of cancer cells. It is therefore important to elucidate the mechanisms underlying the regulation of Bmi-1 expression both under normal growth conditions and in malignant tissues. In the present review, the current body of knowledge pertaining to the transcriptional and post-transcriptional regulation of the $B M I-1$ gene is discussed, and the potential mechanisms by which Bmi-1 is dysregulated in various types of cancer are highlighted. Bmi-1 expression is primarily controlled via transcriptional regulation, and is regulated by the transcrip-
\end{abstract}

Correspondence to: Dr Lingyu Luo, Department of Gastroenterology, Research Institute of Digestive Diseases, The First Affiliated Hospital of Nanchang University, 17 Yongwaizen Street, Nanchang, Jiangxi 330006, P.R. China

E-mail: luolingyu@ncu.edu.cn

Abbreviations: PcG, polycomb group; Bmi-1, B lymphoma Mo-MLV insertion region 1 homolog; PRC, polycomb repressive complex; E2F, E2 promoter binding factor; EMT, epithelial to mesenchymal transition, SALL4, Sal-like protein 4; NLS, nuclear localization signal; PEST, a peptide sequence that is rich in proline (P), glutamic acid (E), serine (S), and threonine (T); IKK $\alpha$, IкB kinase $\alpha$; GLI, glioma-associated oncogene; KLF4, Krüppel-like factor 4; HDACi, histone deacetylase inhibitors; miRNAs, microRNAs; UTR, untranslated region

Key words: BMI-1, polycomb repressive complex, gene transcription, microRNA, transcriptional regulation, post-transcriptional regulation tion https://www.ushuaia.pl/hyphen/?ln=en factors of the Myc family, including Myb, Twist1, SALL4 and E2F-1. Post-transcriptionally, regulation of Bmi-1 expression is inhibited by several microRNAs and certain small-molecule drugs. Thus, regulatory transcriptional factors are potential therapeutic targets to reduce Bmi-1 expression in cancer cells. Thus, the present review provides an up-to-date review on the regulation of BMI-1 gene expression at the transcriptional and post-transcriptional level.

\section{Contents}

1. Introduction

2. Bmi-1 protein structure

3. Transcriptional regulation of the $B M I-1$ gene

4. Regulation of Bmi-1 at the post-transcriptional level

5. Conclusion and future prospects

\section{Introduction}

The polycomb group (PcG) is a class of highly conserved transcriptional repressors. They are divided into two core protein complexes: Polycomb repressive complex (PRC)1 and PRC2. Both PRC1 and PRC2 serve an important role in the maintenance of the inhibition state of chromatins by polycomb proteins. PRC2 binds to the target gene during the initial stage of transcription and recruits the PRC1 complex to bind to the target gene, which maintains the repressed state of the gene (1).

The PRC1 complex core proteins include RING1B (also referred to as RNF2), RING1A (also referred to as RING1), B lymphoma Mo-MLV insertion region 1 homolog (Bmi-1), EDR1 (also referred to as HPH1) and CBX4 (also referred to as HPC2). Among these components, Bmi-1 serves a pivotal role in the PRC1 complex (1). The binding of Bmi-1 to chromatin along with other PcG proteins of the PRC1 complex leads to histone $\mathrm{H} 3 \mathrm{~K} 27$ methylation, which results in continued silencing of the Ink4a/Arf locus. Decreased levels of p16Ink4a and p19Arf lead to activation of nuclear E2F and downregulation of p53 (2), which in turn promotes cell proliferation and self-renewal of cancer stem cells (Fig. 1). In addition, Bmi-1 inhibits the expression of E-cadherin by interacting with epithelial to mesenchymal transition (EMT) regulatory 

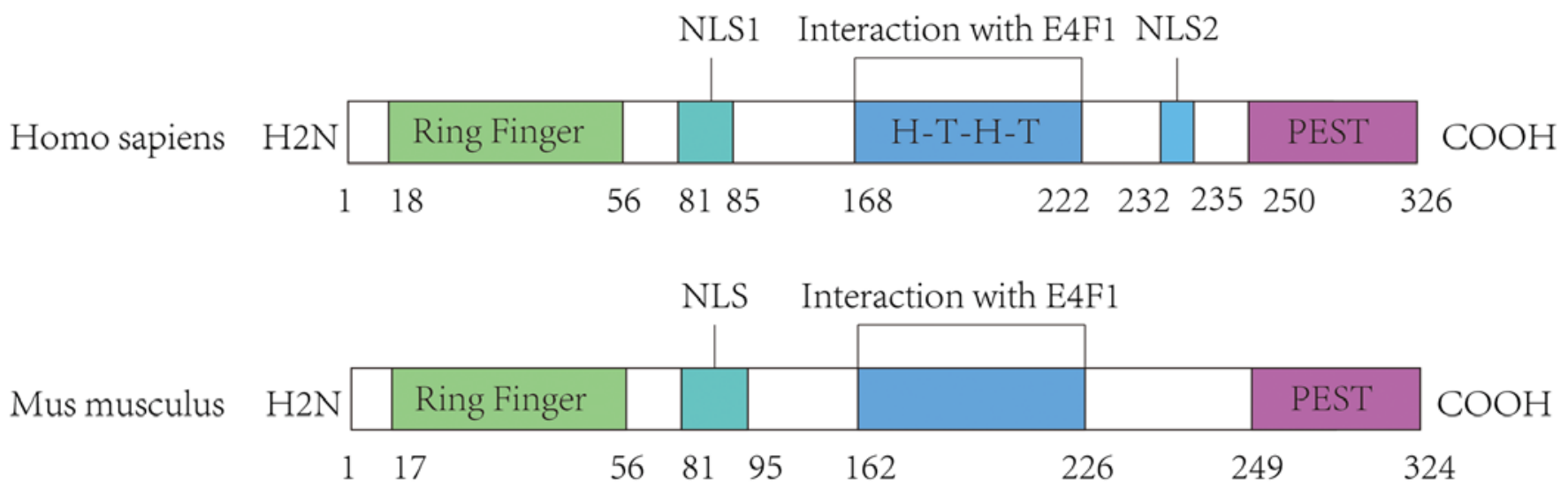

\section{Felis catus}



Figure 1. Function of Bmi-1. The PRC1 complex core proteins include RING1B (RNF2), RING1A (RING1), Bmi-1, EDR1 (HPH1) and CBX4 (HPC2). The binding of Bmi-1 to chromatin along with other PcG proteins of the PRC1 complex results in continued silencing of the Ink4a/Arf locus. Decreased levels of p16Ink4a and p19Arf lead to activation of nuclear E2F and downregulation of p53, which in turn promotes cell proliferation and self-renewal of cancer stem cells, and inhibit apoptosis. Bmi-1, B lymphoma Mo-MLV insertion region 1 homolog; PRC, polycomb repressive complex; E2F, E2 promoter binding factor; $\mathrm{ROS}$, reactive oxygen species; $\mathrm{Rb}$, retinoblastoma protein.

molecules, such as Twist1, Wnt, Snail and $\beta$-catenin to induce EMT, whereas inhibition of Bmi-1 expression leads to EMT reversal and decreased cell migratory ability (3). $B M I-1$ is a highly conserved gene with rare mutations. It serves as a central node of various oncogenes and plays an important role in cell proliferation and tumorigenesis. Multiple signaling pathways, including N-Myc (MYCN), c-Myc, (MYC) (4), twist (3), Akt (5), and MAPK upregulate BMI-1 expression. Under normal growth conditions, BMI-1 expression is maintained within physiological levels through a feed-back loop that involves the PcG family members, PRC1 and PRC2 (6). However, $B M I-1$ expression is upregulated in malignant cells, partly due to stimulation by oncogenes, such as $E 2 F-1$ and $c-M Y C$, and this allows for the maintenance of an undifferentiated state of the cells. BMI-1 overexpression is a biomarker of malignant tumors and is closely related to tumor malignancy, invasion, metastasis and prognosis (7). Therefore, inhibition of BMI-1 expression, restoration of p16Ink4a and p19Arf levels, and induction of cellular senescence are novel potential therapeutic targets for anti-cancer targeted therapy (8).

Bmi-1 is a short-lived protein, and its expression levels are controlled by various mechanisms. Bmi-1 expression is primarily controlled by transcriptional and post-transcriptional regulation $(1,8)$. Transcriptional regulation of eukaryotic genes involves DNA methylation, histone modification, chromatin remodeling and transcription factors. Post-transcriptional regulation is predominantly achieved through regulation of RNA, which includes RNA processing and maturation, RNA transport and subcellular localization, mRNA translation and mRNA degradation (9). In this review, the recent advances in the understanding of transcriptional (Table I) and post-transcriptional regulation (Table II) of BMI-1 expression are summarized.

\section{Bmi-1 protein structure}

The BMI-1 gene was identified as a common provirus-binding site during induction of B cell lymphoma using Moroni's murine leukemia virus in transgenic mice (10). The human $B M I-1$ gene is very similar to its mouse homolog and is located in the short arm 13 region of chromosome 10 (10p13). The cDNA length of human BMI-1 gene is 3,203 bp with $86 \%$ similarity with the mouse gene sequence. The human $B M I-1$ gene consists of 10 exons, which encode a protein containing 326 amino acids with $98 \%$ amino acid sequence homology with mouse Bmi-1 (11). Bmi-1 protein structure is divided into the amino terminus, the central region and the carboxyl terminus (Fig. 2). The amino terminus has a Ring Finger domain consisting of a cysteine-rich zinc finger motif and $\mathrm{C} 3 \mathrm{HC} 4$ (12). The central region is a conserved helix-tu rn-helix-turn-helix-turn (HTHTHT) domain; the carboxyl terminus is considered a peptide sequence that is rich in proline $(\mathrm{P})$, glutamic acid $(\mathrm{E})$, serine $(\mathrm{S})$, and threonine $(\mathrm{T})$ (PEST) sequence. The nuclear localization signal sequence (NLS)1 (KRRR) and NLS2 (KRMK) are both located between the three regions (13). Each region has a different function, and the function of the loop finger domain is to bind to DNA and exert transcriptional regulation (14), which is also required for the activation of E3 ubiquitin ligase activity (15). The HTHTHT domain is the key structure involved in the gene transcriptional repressor function of Bmi-1 (14); the NLS consists of a short-chain amino acids that is involved in the nuclear localization of the Bmi-1 protein. The carboxy-terminal PEST region is enriched with proline, glutamic acid, serine and threonine, and is involved in the rapid intracellular degradation of Bmi-1 (16). 
Table I. Factors that regulate $B M I-1$ expression at the transcriptional level.

\begin{tabular}{|c|c|c|}
\hline Factors & Function & (Refs.) \\
\hline c-Myc & Increases Bmi-1 expression by binding to the E-box sequence in the $B M I-1$ promoter & $(18,19)$ \\
\hline N-Myc & Increases Bmi-1 expression by binding to the E-box sequence in the $B M I-1$ promoter & $(22,23)$ \\
\hline c-Myb & Increases Bmi-1 expression by binding 5 '-flanking region nucleotides +3 to +8 & $(31)$ \\
\hline Twist1 & Increases Bmi-1 expression by binding the E-box sequence in intron 1 of $B M I-1$ gene & (3) \\
\hline SALL4 & Binds to the -450 to -1 region of the $B M I-1$ promoter and increases $B m i-1$ transcription & $(36)$ \\
\hline E2F-1 & $\begin{array}{l}\text { Combines with the E2F-1 binding site in } B M I-1 \text { promoter to increase } \\
\text { BMI-1 transcriptional activity }\end{array}$ & $(38,40)$ \\
\hline Hedgehog signal & $\begin{array}{l}\text { Hedgehog downstream protein GLI1 binds to BMI-1 promoter and } \\
\text { increases Bmi-1 transcription }\end{array}$ & (44) \\
\hline FoxM1c & Promotes Bmi-1 expression by increasing c-Myc expression & $(28)$ \\
\hline Estrogen receptor $\alpha$ & $\begin{array}{l}\text { Interacts with the } B M I-1 \text { promoter upstream element at }-327 \text { to }-172 \text { bp } \\
\text { to activate } B M I-1 \text { transcription }\end{array}$ & $(45)$ \\
\hline Sp1 & $\begin{array}{l}\text { Binds to the region from }+181 \text { to }+214 \text { within the } B M I-1 \text { promoter and increases } \\
B M I-1 \text { transcriptional activity }\end{array}$ & (46) \\
\hline Nrf2 & Promotes $B M I-1$ transcription via an unknown mechanism & (49) \\
\hline Id 1 & Promotes Bmi-1 expression by increasing c-Myc expression & (49) \\
\hline Mel-18 & Suppresses Bmi-1 expression via inhibition of c-Myc expression & $(20,26)$ \\
\hline HDACi & Indirectly inhibits $B M I-1$ promoter activity & $(50)$ \\
\hline KLF4 & Binds to the $B M I-1$ promoter sequence, -233 to 0 , to suppress $B M I-1$ transcription & $(47)$ \\
\hline Copper sulfate & Inhibits Bmi-1 expression via an unknown mechanism & $(70)$ \\
\hline
\end{tabular}

Bmi-1, B lymphoma Mo-MLV insertion region 1 homolog; E2F, E2 promoter binding factor; SALL4, Sal-like protein 4; Id1, inhibitor of differentiation and DNA binding; HDACi, histone deacetylase inhibitor; KLF4, Krüppel-like factor 4.

Table II. Factors that regulate BMI-1 expression at the post-transcriptional level.

\begin{tabular}{|c|c|c|}
\hline Factors & Cell or tissue types & (Refs.) \\
\hline miR-15a & $\begin{array}{l}\text { Gastric tumor tissues } \\
\text { Prostate tumor tissues }\end{array}$ & $\begin{array}{l}(58) \\
(71)\end{array}$ \\
\hline miR-16 & Ovarian cancer tissues & $(53,66)$ \\
\hline miR-30d & Prostate cancer & $(61)$ \\
\hline $\operatorname{miR}-30 \mathrm{e}^{*}$ & Tumor-associated macrophages in gastrointestinal cancer & $(61)$ \\
\hline $\operatorname{miR}-34 a$ & Brain tumor; breast cancer & $(54,72)$ \\
\hline $\operatorname{miR}-128$ & Brain tumor & $(54)$ \\
\hline miR-135a & Pancreatic ductal adenocarcinoma & $(56)$ \\
\hline miR-141 & Human diploid fibroblasts & $(60)$ \\
\hline miR-183 & Gastric cancer & $(57)$ \\
\hline miR-194 & Endometrial cancer cell lines & $(59)$ \\
\hline miR-200b & Prostate cancer & $(62)$ \\
\hline $\operatorname{miR}-200 \mathrm{c}$ & Melanoma & $(65)$ \\
\hline miR-203 & Leukemia stem cells & (63) \\
\hline miR-218 & Colon cancer & $(55)$ \\
\hline miR-221 & prostate cancer & (71) \\
\hline miR-302 & MCF7, HepG2 Cell lines & (73) \\
\hline miR-320a & Nasopharyngeal carcinoma. & $(60)$ \\
\hline $\operatorname{miR}-452$ & Colorectal cancer; glioma & $(74,75)$ \\
\hline miR-495 & Mesenchymal stem cells & $(76)$ \\
\hline NVP-LDE-225 & Prostate cancer & $(32)$ \\
\hline PTC-209 & Colorectal cancer & $(68)$ \\
\hline
\end{tabular}

miR, microRNA. 


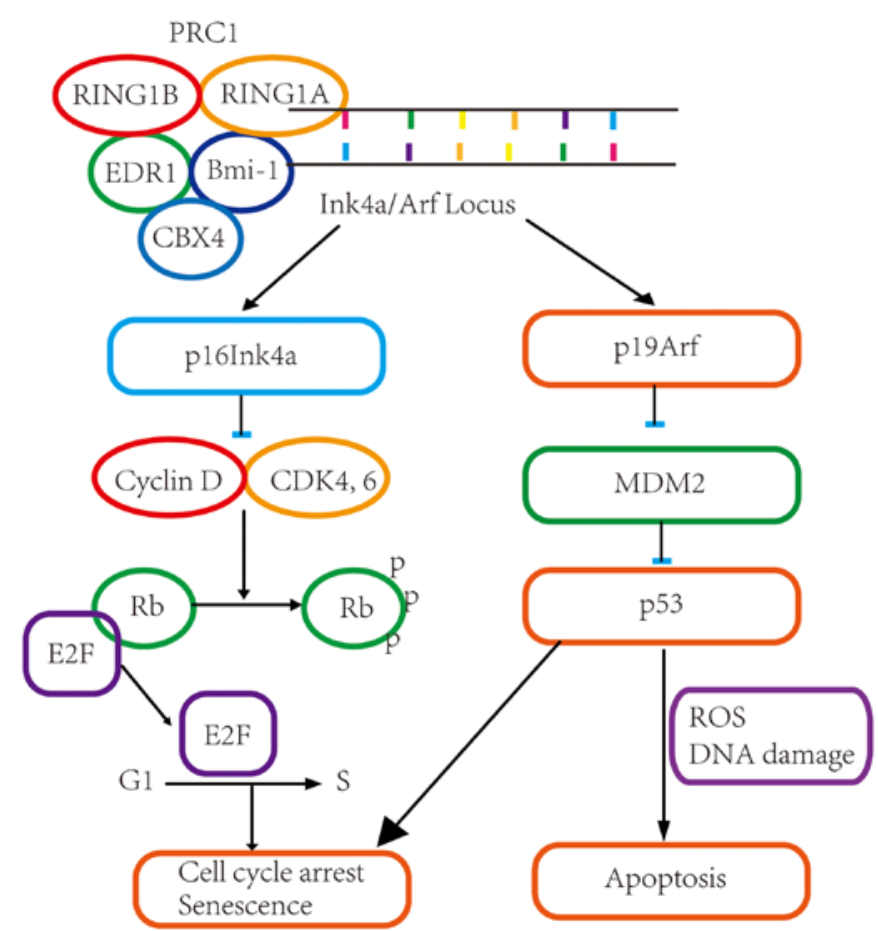

Figure 2. Schematic illustration of the structure of the BMI-1 gene in homo sapiens, mus musculus and felis catus. NLS, nuclear localization signal; E2F1, E2 promoter binding factor-1; PEST, a peptide sequence that is rich in proline $(\mathrm{P})$, glutamic acid $(\mathrm{E})$, serine $(\mathrm{S})$, and threonine $(\mathrm{T})$.

\section{Transcriptional regulation of the $B M I-1$ gene}

Transcriptional regulation is the primary mechanism by which $B M I-1$ expression is controlled. The transcription factors that regulate $B M I-1$ include members of the Myc family, Myb, Twist1, SALL4 and E2F-1 (Fig. 3).

Myc family. The Myc family is a group of important oncogenes, including MYC, MYCN, L-Myc, S-Myc and B-Myc. Of these, MYC and MYCN are involved in BMI-1 transcription (4). MYC plays an important role in cell proliferation, differentiation and apoptosis, and is abnormally expressed in several types of cancer (17). In murine lymphoma and human malignant glioma, both $M Y C$ and BMI-1 are highly expressed, and exhibit a positive correlation with each other $(18,19)$. The MYC protein is a transcription factor of the basic helix-loop-helix leucine zipper family. MYC forms a functional DNA-binding complex with Max, another member of the same family, and this complex specifically recognizes the E-box sequence (CACGTG) of the BMI-1 gene promoter, thereby increasing the expression of $B M I-1$ at the transcriptional level $(4,19,20)$.

Another member of the Myc family, $M Y C N$, is frequently upregulated in human neuroblastoma (21). MYCN protein has been shown to be associated with Bmi-1 expression in orthotopic neuroblastoma cell lines and tumor samples. In addition, $M Y C N$ protein expression was shown to increase the transcriptional activity of $B M I-1$ gene by binding to the $B M I-1$ promoter E-box region (22). Overexpression of $M Y C N$ promotes tumorigenesis and proliferation of neuroblastoma cells by directly targeting and upregulating BMI-1 (23).

Other factors regulate BMI-1 indirectly through the Myc gene family. Mel-18 protein is a member of the PcG family that possesses close structural similarities with the Bmi-1 protein (24); however, functionally, it cannot replace the role of Bmi-1 in PRC1 (6). Mel-18 inhibits transcriptional expression of c-Myc and prevents c-Myc from binding to the $B M I-1$ gene promoter $(4,25)$, which indirectly inhibits $B M I-1$ transcription. Mel-18 is considered a tumor suppressor due to its ability to inhibit the transcription of the $M Y C$ and $B M I-1$ genes, thereby inhibiting the proliferation and inducing apoptosis of cancer cells (20). Induction of overexpression of Mel-18 to downregulate the expression of $B M I-1$ gene was shown to attenuate the malignant attributes of breast cancer cells (26). Furthermore, transcription factor FoxM1c was shown to indirectly increase the expression of $B M I-1$ via c-Myc $(27,28)$.

$M Y B$. c-Myb is a member of the $M Y B$ transcription factor family. It promotes the expression of gut stem cell genes, particularly Lgr5, which affects the self-renewal capacity of intestinal and hematopoietic stem cells (29). In B-lymphocytic leukemia cells, c-Myb binds to the E-box element in the proximal regulatory region of the miR-155 host gene promoter, facilitating its transcription (30). Waldron et al (31) found that c-Myb binds directly to the +3 to +8 nucleotide sequence of the $B M I-15^{\prime}$ flanking region to increase $B M I-1$ transcription, and that c-Myb and Bmi-1 are required for human and mouse p190 BCR/ABL leukemogenesis.

Twist1. Twist1 belongs to the family of basic helix-loop-helix transcription factors. It promotes EMT by inhibiting E-cadherin expression (32). Mechanistically, Twist1 binds directly to the E-cadherin promoter to inhibit its expression, and it also directly binds to the E-box site of the -732 to -727 nucleotide sequence in intron 1 of the BMI-1 promoter to initiate the transcriptional upregulation of the BMI-1 gene (5). Twist1-mediated suppression of E-cadherin and upregulation of Bmi-1 leads to disruption of the tight junction between cells, thereby increasing tumor cell metastasis $(33,35)$.

Sal-like protein 4 (SALL4). SALL4 is a more recently identified zinc finger transcription factor that plays an important role in the maintenance of pluripotency of embryonic stem cells and the self-renewal capacity of hematopoietic stem cells (36). Significant upregulation of SALL4 and Bmi-1 expression has been reported in patients with myeloid leukemia (37). Additionally, high expression levels of these two genes were shown to be associated with the expansion of hematopoietic progenitor cells. This suggests that the expression of SALL4 and Bmi-1 is a prognostic biomarker of acute leukemia. Results of luciferase reporter assays by Yang et al (36) showed that the $B M I-1$ gene is a target of SALL4, and, increased expression of SALL4 was found to upregulate the activity of the BMI-I promoter. Further analysis of the binding sites revealed that the SALL4 protein binds to a functional site in the -450 to -1 nucleotide sequence of the $B M I-1$ promoter to initiate transcription of the BMI-1 gene.

E2 promoter binding factor $(E 2 F)-1$. E2F-1 is a member of the E2F transcription factor family. E2F-1 is involved in cell cycle progression and regulates cell viability via both p53-independent and p53-dependent pathways (38). E2F-1 initiates transcription of the $B M I-1$ gene and upregulates 


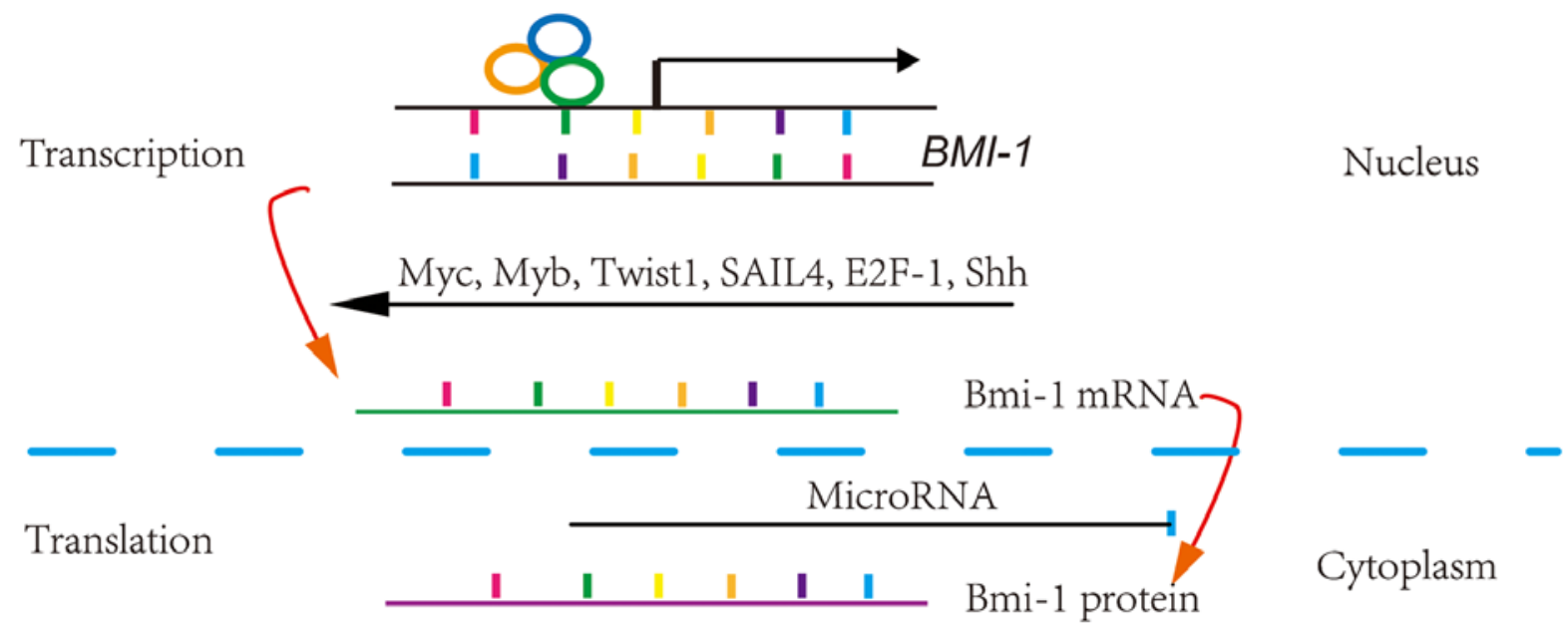

Figure 3. Regulation of BMI-1 expression. The transcription of BMI-1 is regulated by Myc, Myb, Twist1, SALL4, E2F1, Shh. The translation of BMI-1 is regulated by various microRNAs. E2F, E2 promoter binding factor; Shh, sonic hedgehog; SALL4, Sal-like protein 4.

BMI- 1 expression by directly binding to the E2F binding site in the BMI-1 gene promoter; interestingly, when the cell is in the cell cycle or differentiation phase, $B M I-1$ is not regulated by E2F-1 (39). In androgen-deficient prostate cancer cells, the I $\mathrm{B}$ kinase $\alpha(\mathrm{IKK} \alpha)-\mathrm{E} 2 \mathrm{~F} 1-\mathrm{Bmi}-1$ cascade is activated. In these cells, activated IKK $\alpha$ phosphorylates E2F-1 to promote E2F-1 nuclear localization, whereby E2F-1 binds to the co-activator CREB binding protein (histone $\mathrm{H} 3$ acetyltransferase) and recruits the target genes, including $B M I-1$, thereby resulting in activation of BMI-1 (40).

Hedgehog signaling. Hedgehog signaling is a major regulator of vertebrate embryonic development, as it is involved in stem cell maintenance and cell differentiation and proliferation. Abnormal activation of the Hedgehog signaling pathway was shown to be associated with the development of lung, prostate and breast cancer (41). The primary components of the Hedgehog signaling pathway include patched, Smoothened and glioma-associated oncogene (GLI) (42). In a study by Liu et al (43), addition of sonic Hedgehog to activate the Hedgehog signaling pathway increased the expression of Bmi-1, whereas inhibition of the Hedgehog signaling pathway using cyclopamine resulted in downregulated expression of Bmi-1. Wang et al (44) found that GLI1 binds to the promoter of the BMI-1 gene, and that the BMI-1 transcription level changes in accordance with the increase or decrease in GLI1 expression.

Other factors. In addition to the above transcription factors, several other factors may regulate $B M I-1$. Estrogen receptor $\alpha$ activates the transcriptional activity of the $B M I-1$ gene by interacting with the -327 to -172 bp nucleotide sequence upstream of the BMI-1 promoter, thereby increasing BMI-1 gene expression (45). The transcription factor $\mathrm{Sp} 1$ binds to the +181 to +214 region of the BMI-1 promoter and increases $B M I-1$ gene expression (46). Krüppel-like factor 4 (KLF4) is a zinc finger protein that is normally expressed in the intestines and skin, and plays an important role in the regulation of stem cells. Yu et al (47) found that KLF4 binds directly to the -233 to 0 sequence of the $B M I-1$ gene promoter and inhibits the transcriptional activity of $B M I-1$, thereby reducing the expression of Bmi-1. The binding site of KLF4 to the BMI- 1 gene is different from the binding site of c-Myc to the BMI-1 promoter. Redox sensing factor Nrf2 was shown to increase the expression of $B M I-1$ at the transcriptional level, thereby promoting the proliferation of cancer stem cells and inhibiting cancer cell apoptosis (48). The helix-loop-helix inhibitor of differentiation and DNA binding facilitates tumorigenesis by increasing the expression of Bmi-1 via c-Myc (49). Bommi et al (50) found that histone deacetylase inhibitors (HDACi) inhibit BMI-1 gene transcription in breast cancer cells via an indirect mechanism. In certain cancer cell lines, $c-M y c$ is the target gene of HDACi, whereas in breast cancer cells, the inhibitory effect of HDACi on BMI-1 gene expression is not dependent on downregulation of c-Myc; however, the precise mechanism is not clear. Thus, there are various transcription factors that bind the promoter of $B M I-1$ and regulate $B M I-1$ gene expression at the transcriptional level.

\section{Regulation of Bmi-1 at the post-transcriptional level}

Post-transcriptional regulation primary involves the regulation of RNA and is divided into the following steps in chronological order: RNA processing and maturation, RNA transport and subcellular localization, mRNA translation and mRNA degradation. MicroRNAs (miRNAs) block gene expression primarily by preventing mRNA translation and/or promoting mRNA degradation (51). miRNAs are non-coding, short-stranded RNAs, which typically consist of 18-22 nucleotides. An miRNA complements the 3'-untranslated region (UTR) of its target mRNA and directs RNA-induced silencing complex to a specific region of the mRNA, thereby inhibiting mRNA translation or promoting mRNA degradation (8).

Bmi-1 expression is inhibited by several miRNAs, including miR-135a, miR-141, miR-183, miR-15a, miR-194, miR-203, miR-200b, miR-320a, miR-200c, miR-16, miR-495, miR-221, miR-30d, miR-128a, miR-34a, miR-452, miR-302 and miR-30e (51-67). For example, the expression of miR-218 in cancer tissues is lower than that in the paratumoral normal 
tissues, whereas the expression of Bmi-1 in cancer tissues is higher than that in the paratumoral normal tissues. An inverse correlation between Bmi-1 expression and miR-128 has been demonstrated in glioma and rectal cancer cells. Results of luciferase reporter assays showed that miR-128 inhibits Bmi-1 protein expression by binding to the 476 to 488 region of BMI-1 3'-UTR (54). several transcription factors and cytokines affect the expression levels of Bmi-1 by altering the expression of miRNAs. For example, Zeb1 was shown to downregulate Bmi-1 expression by inducing upregulation of the expressions of miR-203 and miR-183 (32).

\section{Conclusion and future prospects}

The polycomb family protein member Bmi-1 acts as an oncogene and maintains the undifferentiated state of malignant tumor cells. Bmi-1 expression levels are closely related to the degree of malignancy, invasion and metastasis, and is a biomarker of adverse prognosis in cancer patients. As a pivotal node of multiple signaling pathways, Bmi-1 regulates the function of several downstream transcription factors and cytokines. Therefore, inhibition of Bmi-1 expression is a promising strategy for anticancer drug development. It has been shown that NVP-LDE-225 (Erismodegib) inhibits Bmi-1 expression by inducing upregulation of miR-128 (68). In addition, PTC-209 is a small molecule drug that specifically inhibits Bmi-1 expression at the post-transcriptional level by binding to the $5^{\prime}$ and $3^{\prime}$ non-coding regions of BMI-1 mRNA (69). Transcriptional and post-transcriptional regulation are the primary means of regulation of Bmi-1 expression. Therefore, regulatory factors are potential therapeutic targets to reduce Bmi-1 expression in cancer cells.

\section{Acknowledgements}

Not applicable.

\section{Funding}

This study was supported by the National Nature Science Foundation of China (grant no. 82060450), Nature Science Foundation of Jiangxi province of China (grant nos. 20192BAB205072 and 20181BAB205050), and The Education Department of Jiangxi Province of China (grant no. 160032).

\section{Availability of data and materials}

Not applicable.

\section{Authors' contributions}

MZ and QX searched the literature, reviewed the articles and collected the relevant data from the selected papers. DH and LL wrote the manuscript. All authors have read and approved the final manuscript.

\section{Ethics approval and consent to participate}

Not applicable.

\section{Patient consent for publication}

Not applicable.

\section{Competing interests}

All authors declare no competing interests.

\section{References}

1. Park IK, Qian D, Kiel M, Becker MW, Pihalja M, Weissman IL, Morrison SJ and Clarke MF: Bmi-1 is required for maintenance of adult self-renewing haematopoietic stem cells. Nature 423: 302-305, 2003.

2. Park IK, Morrison SJ and Clarke MF: Bmil, stem cells, and senescence regulation. J Clin Invest 113: 175-179, 2004.

3. Yang MH, Hsu DS, Wang HW, Wang HJ, Lan HY, Yang WH, Huang $\mathrm{CH}$, Kao SY, Tzeng CH, Tai SK, et al: Bmil is essential in Twistl-induced epithelial-mesenchymal transition. Nat Cell Biol 12: 982-992, 2010. Erratum in: Nat Cell Biol 21: 533, 2019.

4. Adhikary S and Eilers M: Transcriptional regulation and transformation by Myc proteins. Nat Rev Mol Cell Biol 6: 635-645, 2005.

5. Kim J, Hwangbo J and Wong PK: p38 MAPK-Mediated Bmi-1 down-regulation and defective proliferation in ATM-deficient neural stem cells can be restored by Akt activation. PLoS One 6: e16615, 2011.

6. Cao R, Tsukada Y and Zhang Y: Role of Bmi-1 and Ring1A in H2A ubiquitylation and Hox gene silencing. Mol Cell 20: $845-854,2005$

7. Bhattacharyya J, Mihara K, Ohtsubo M, Yasunaga S, Takei Y, Yanagihara K, Sakai A, Hoshi M, Takihara Y and Kimura A: Overexpression of BMI-1 correlates with drug resistance in B-cell lymphoma cells through the stabilization of survivin expression. Cancer Sci 103: 34-41, 2012.

8. Cao L, Bombard J, Cintron K, Sheedy J, Weetall ML and Davis TW: BMI1 as a novel target for drug discovery in cancer. J Cell Biochem 112: 2729-2741, 2011.

9. Venkatesh S and Workman JL: Histone exchange, chromatin structure and the regulation of transcription. Nat Rev Mol Cell Biol 16: 178-189, 2015.

10. Siddique HR, Parray A, Tarapore RS, Wang L, Mukhtar H, Karnes RJ, Deng Y, Konety BR and Saleem M: BMI1 polycomb group protein acts as a master switch for growth and death of tumor cells: Regulates TCF4-transcriptional factor-induced BCL2 signaling. PLoS One 8: e60664, 2013.

11. Alkema MJ, Wiegant J, Raap AK, Berns A and van Lohuizen M: Characterization and chromosomal localization of the human proto-oncogene BMI-1. Hum Mol Genet 2: 1597-1603, 1993.

12. Freemont PS, Hanson IM and Trowsdale J: A novel cysteine-rich sequence motif. Cell 64: 483-484, 1991.

13. Dimri GP, Martinez JL, Jacobs JJL, Keblusek P, Itahana K, Van Lohuizen M, Campisi J, Wazer DE and Band V: The Bmi-l oncogene induces telomerase activity and immortalizes human mammary epithelial cells. Cancer Res 62: 4736-4745, 2002.

14. Cohen KJ, Hanna JS, Prescott JE and Dang CV: Transformation by the Bmi-1 oncoprotein correlates with its subnuclear localization but not its transcriptional suppression activity. Mol Cell Biol 16: 5527-5535, 1996.

15. Buchwald G, van der Stoop P, Weichenrieder O, Perrakis A, van Lohuizen M and Sixma TK: Structure and E3-ligase activity of the Ring-Ring complex of polycomb proteins Bmil and Ring1b. EMBO J 25: 2465-2474, 2006.

16. Rogers S, Wells R and Rechsteiner M: Amino acid sequences common to rapidly degraded proteins: The PEST hypothesis. Science 234: 364-368, 1986.

17. Hoffman B and Liebermann DA: Apoptotic signaling by c-MYC. Oncogene 27: 6462-6472, 2008.

18. Jacobs JJL, Scheijen B, Voncken JW, Kieboom K, Berns A and van Lohuizen M: Bmi-1 collaborates with c-Myc in tumorigenesis by inhibiting c-Myc-induced apoptosis via INK4a/ARF Genes Dev 13: 2678-2690, 1999.

19. Cenci T, Martini M, Montano N, D'Alessandris QG, Falchetti ML, Annibali D, Savino M, Bianchi F, Pierconti F, Nasi S, et al: Prognostic relevance of c-Myc and BMI1 expression in patients with glioblastoma. Am J Clin Pathol 138: 390-396, 2012. 
20. Guo WJ, Datta S, Band V and Dimri GP: Mel-18, a polycomb group protein, regulates cell proliferation and senescence via transcriptional repression of Bmi-1 and c-Myc oncoproteins. Mol Biol Cell 18: 536-546, 2007.

21. Weiss WA, Aldape K, Mohapatra G, Feuerstein BG and Bishop JM: Targeted expression of MYCN causes medulloblastoma in transgenic mice. EMBO J 16: 2985-2995, 1997.

22. Ochiai H, Takenobu H, Nakagawa A, Yamaguchi Y, Kimura M, Ohira M, Okimoto Y, Fujimura Y, Koseki H, Kohno Y, et al: Bmil is a MYCN target gene that regulates tumorigenesis through repression of $K I F I B \beta$ and TSLC1 in neuroblastoma. Oncogene 29: 2681-2690, 2010.

23. Huang R, Cheung NKV, Vider J, Cheung IY, Gerald WL, Tickoo SK, Holland EC and Blasberg RG: MYCN and MYC regulate tumor proliferation and tumorigenesis directly through BMI1 in human neuroblastomas. FASEB J 25: 4138-4149, 2011.

24. Ishida A, Asano H, Hasegawa M, Koseki H, Ono T, Yoshida MC, Taniguchi $\mathrm{M}$ and Kanno M: Cloning and chromosome mapping of the human Mel-18 gene which encodes a DNA-binding protein with a new 'RING-finger' motif. Gene 129: 249-255, 1993.

25. Tetsu $O$, Ishihara $H$, Kanno R, Kamiyasu M, Inoue H, Tokuhisa $T$, Taniguchi M and Kanno M: mel-18 negatively regulates cell cycle progression upon B cell antigen receptor stimulation through a cascade leading to c-myc/cdc25. Immunity 9: 439-448, 1998.

26. Guo WJ, Zeng MS, Yadav A, Song LB, Guo BH, Band V and Dimri GP: Mel-18 acts as a tumor suppressor by repressing Bmi-1 expression and down-regulating Akt activity in breast cancer cells. Cancer Res 67: 5083-5089, 2007.

27. Liu-Bryan R and Terkeltaub R: Chondrocyte innate immune myeloid differentiation factor 88 -dependent signaling drives procatabolic effects of the endogenous Toll-like receptor 2/Toll-like receptor 4 ligands low molecular weight hyaluronan and high mobility group box chromosomal protein 1 in mice. Arthritis Rheum 62: 2004-2012, 2010.

28. Li SKM, Smith DK, Leung WY, Cheung AM, Lam EW, Dimri GP and Yao KM: FoxM1c counteracts oxidative stress-induced senescence and stimulates Bmi-1 expression. J Biol Chem 283: 16545-16553, 2008.

29. Cheasley D, Pereira L, Lightowler S, Vincan E, Malaterre J and Ramsay RG: Myb controls intestinal stem cell genes and self-renewal. Stem Cells 29: 2042-2050, 2011.

30. Vargova K, Curik N, Burda P, Basova P, Kulvait V, Pospisil V, Savvulidi F, Kokavec J, Necas E, Berkova A, et al: MYB transcriptionally regulates the miR-155 host gene in chronic lymphocytic leukemia. Blood 117: 3816-3825, 2011.

31. Waldron T, De Dominici M, Soliera AR, Audia A, Iacobucci I, Lonetti A, Martinelli G, Zhang Y, Martinez R, Hyslop T, et al: $\mathrm{c}-\mathrm{Myb}$ and its target Bmil are required for p190BCR/ABL leukemogenesis in mouse and human cells. Leukemia 26: 644-653, 2012.

32. Martin A and Cano A: Tumorigenesis: Twist1 links EMT to self-renewal. Nat Cell Biol 12: 924-925, 2010.

33. Yang MH, Hsu DSS, Wang HW, Wang HJ, Lan HY, Yang WH Huang $\mathrm{CH}$, Kao SY, Tzeng $\mathrm{CH}$, Tai SK, et al: Bmil is essential in Twist1-induced epithelial-mesenchymal transition. Nat Cell Biol 12: 982-992, 2010

34. Wu KJ: Direct activation of Bmil by Twist1: Implications in cancer stemness, epithelial-mesenchymal transition, and clinical significance. Chang Gung Med J 34: 229-238, 2011.

35. Wu CY, Hung JJ and Wu KJ: Linkage between Twist1 and Bmi1: Molecular mechanism of cancer metastasis/stemness and clinical implications. Clin Exp Pharmacol Physiol 39: 668-673, 2012.

36. Yang J, Chai L, Liu F, Fink LM, Lin P, Silberstein LE, Amin HM, Ward DC and Ma Y: Bmi-1 is a target gene for SALL4 in hematopoietic and leukemic cells. Proc Natl Acad Sci USA 104 10494-10499, 2007.

37. Vander Griend DJ, D'Antonio J, Gurel B, Antony L, Demarzo AM and Isaacs JT: Cell-autonomous intracellular androgen receptor signaling drives the growth of human prostate cancer initiating cells. Prostate 70: 90-99, 2010.

38. Irwin M, Marin MC, Phillips AC, Seelan RS, Smith DI, Liu W, Flores ER, Tsai KY, Jacks T, Vousden KH, et al: Role for the p53 homologue p73 in E2F-1-induced apoptosis. Nature 407: 645-648, 2000

39. Nowak K, Kerl K, Fehr D, Kramps C, Gessner C, Killmer K, Samans B, Berwanger B, Christiansen $\mathrm{H}$ and Lutz W: BMII is a target gene of E2F-1 and is strongly expressed in primary neuroblastomas. Nucleic Acids Res 34: 1745-1754, 2006.

40. Ammirante M, Kuraishy AI, Shalapour S, Strasner A, Ramirez-Sanchez C, Zhang W, Shabaik A and Karin M: An IKK $\alpha$-E2F1-BMI1 cascade activated by infiltrating B cells controls prostate regeneration and tumor recurrence. Genes Dev 27: 1435-1440, 2013.
41. Gupta S, Takebe N and Lorusso P: Targeting the Hedgehog pathway in cancer. Ther Adv Med Oncol 2: 237-250, 2010.

42. Briscoe J and Thérond PP: The mechanisms of Hedgehog signalling and its roles in development and disease. Nat Rev Mol Cell Biol 14: 416-429, 2013.

43. Liu S, Dontu G, Mantle ID, Patel S, Ahn NS, Jackson KW, Suri $\mathrm{P}$ and Wicha MS: Hedgehog signaling and Bmi-1 regulate self-renewal of normal and malignant human mammary stem cells. Cancer Res 66: 6063-6071, 2006.

44. Wang $X$, Venugopal C, Manoranjan B, McFarlane N, O'Farrell E, Nolte S, Gunnarsson T, Hollenberg R, Kwiecien J, Northcott $\mathrm{P}$, et al: Sonic hedgehog regulates Bmil in human medulloblastoma brain tumor-initiating cells. Oncogene 31: 187-199, 2012.

45. Wang H, Liu H, Li X, Zhao J, Zhang H, Mao J, Zou Y, Zhang H, Zhang S, Hou W, et al: Estrogen receptor $\alpha$-coupled Bmil regulation pathway in breast cancer and its clinical implications. BMC Cancer 14: 122, 2014

46. Wang HB, Liu GH, Zhang H, Xing S, Hu LJ, Zhao WF, Xie B, $\mathrm{Li} \mathrm{MZ}$, Zeng $\mathrm{BH}, \mathrm{Li} \mathrm{Y}$, et al: $\mathrm{Sp1}$ and c-Myc regulate transcription of BMI1 in nasopharyngeal carcinoma. FEBS J 280: 2929-2944, 2013

47. Yu T, Chen X, Zhang W, Colon D, Shi J, Napier D, Rychahou P, Lu W, Lee EY, Weiss HL, et al: Regulation of the potential marker for intestinal cells, Bmi1, by $\beta$-catenin and the zinc finger protein KLF4: Implications for colon cancer. J Biol Chem 287: $3760-3768,2012$

48. Jia Y, Chen J, Zhu H, Jia ZH and Cui MH: Aberrantly elevated redox sensing factor $\mathrm{Nrf} 2$ promotes cancer stem cell survival via enhanced transcriptional regulation of ABCG2 and Bcl-2/Bmi-1 genes. Oncol Rep 34: 2296-2304, 2015.

49. Qian T, Lee JY, Park JH, Kim HJ and Kong G: Id1 enhances RING1b E3 ubiquitin ligase activity through the Mel-18/Bmi-1 polycomb group complex. Oncogene 29: 5818-5827, 2010.

50. Bommi PV, Dimri M, Sahasrabuddhe AA, Khandekar J and Dimri GP: The polycomb group protein BMI1 is a transcriptional target of HDAC inhibitors. Cell Cycle 9: 2663-2673, 2010.

51. Slaby O, Svoboda M, Michalek J and Vyzula R: MicroRNAs in colorectal cancer: Translation of molecular biology into clinical application. Mol Cancer 8: 102, 2009.

52. Bhattacharyya J, Mihara K, Yasunaga S, Tanaka H, Hoshi M, Takihara Y and Kimura A: BMI-1 expression is enhanced through transcriptional and posttranscriptional regulation during the progression of chronic myeloid leukemia. Ann Hematol 88: 333-340, 2009

53. Ambros V: The functions of animal microRNAs. Nature 431 $350-355,2004$

54. Godlewski J, Nowicki MO, Bronisz A, Williams S, Otsuki A, Nuovo G, Raychaudhury A, Newton HB, Chiocca EA and Lawler S: Targeting of the Bmi-1 oncogene/stem cell renewal factor by microRNA-128 inhibits glioma proliferation and self-renewal. Cancer Res 68: 9125-9130, 2008.

55. He X, Dong Y, Wu CW, Zhao Z, Ng SS, Chan FK, Sung JJ and Yu J: MicroRNA-218 inhibits cell cycle progression and promotes apoptosis in colon cancer by downregulating BMI1 polycomb ring finger oncogene. Mol Med 18: 1491-1498, 2013.

56. Dang Z, Xu WH, Lu P, Wu N, Liu J, Ruan B, Zhou L, Song WJ and Dou KF: MicroRNA-135a inhibits cell proliferation by targeting Bmil in pancreatic ductal adenocarcinoma. Int J Biol Sci 10: 733-745, 2014.

57. Xu L, Li Y, Yan D, He J and Liu D: MicroRNA-183 inhibits gastric cancer proliferation and invasion via directly targeting Bmi-1. Oncol Lett 8: 2345-2351, 2014.

58. Wu C, Zheng X, Li X, Fesler A, Hu W, Chen L, Xu B, Wang Q, Tong A, Burke S, et al: Reduction of gastric cancer proliferation and invasion by miR-15a mediated suppression of Bmi-1 translation. Oncotarget 7: 14522-14536, 2016.

59. Dong P, Kaneuchi M, Watari H, Hamada J, Sudo S, Ju J and Sakuragi N: MicroRNA-194 inhibits epithelial to mesenchymal transition of endometrial cancer cells by targeting oncogene BMI-1. Mol Cancer 10: 99, 2011.

60. Dimri M, Carroll JD, Cho JH and Dimri GP: microRNA-141 regulates BMI1 expression and induces senescence in human diploid fibroblasts. Cell Cycle 12: 3537-3546, 2013.

61. Sugihara $H$, Ishimoto $T$, Watanabe $M$, Sawayama $H$, Iwatsuki M, Baba Y, Komohara Y, Takeya M and Baba H: Identification of miR-30e ${ }^{*}$ regulation of Bmil expression mediated by tumorassociated macrophages in gastrointestinal cancer. PLoS One 8: e81839, 2013

62. Yu J, Lu Y, Cui D, Li E, Zhu Y, Zhao Y, Zhao F and Xia S: miR-200b suppresses cell proliferation, migration and enhances chemosensitivity in prostate cancer by regulating Bmi-1. Oncol Rep 31: 910-918, 2014 
63. Zhang Y, Zhou SY, Yan HZ, Xu DD, Chen HX, Wang XY, Wang X, Liu YT, Zhang L, Wang S, et al: miR-203 inhibits proliferation and self-renewal of leukemia stem cells by targeting survivin and Bmi-1. Sci Rep 6: 19995, 2016.

64. Qi X, Li J, Zhou C, Lv C and Tian M: MicroRNA-320a inhibits cell proliferation, migration and invasion by targeting BMI-1 in nasopharyngeal carcinoma. FEBS Lett 588: 3732-3738, 2014.

65. Liu S, Tetzlaff MT, Cui R and Xu X: miR-200c inhibits melanoma progression and drug resistance through down-regulation of BMI-1. Am J Pathol 181: 1823-1835, 2012.

66. Bhattacharya R, Nicoloso M, Arvizo R, Wang E, Cortez A, Rossi S, Calin GA and Mukherjee P: miR-15a and miR-16 control Bmi-1 expression in ovarian cancer. Cancer Res 69: 9090-9095, 2009.

67. Venkataraman S, Alimova I, Fan R, Harris P, Foreman N and Vibhakar R: MicroRNA 128a increases intracellular ROS level by targeting Bmi-1 and inhibits medulloblastoma cancer cell growth by promoting senescence. PLoS One 5: e10748, 2010.

68. Nanta R, Kumar D, Meeker D, Rodova M, Van Veldhuizen PJ, Shankar S and Srivastava RK: NVP-LDE-225 (Erismodegib) inhibits epithelial-mesenchymal transition and human prostate cancer stem cell growth in NOD/SCID IL2R $\gamma$ null mice by regulating Bmi-1 and microRNA-128. Oncogenesis 2: e42, 2013.

69. Kreso A, van Galen P, Pedley NM, Lima-Fernandes E, Frelin C, Davis T, Cao L, Baiazitov R, Du W, Sydorenko N, et al: Self-renewal as a therapeutic target in human colorectal cancer. Nat Med 20: 29-36, 2014.

70. Li Y, Hu J, Guan F, Song L, Fan R, Zhu H, Hu X, Shen E and Yang B: Copper induces cellular senescence in human glioblastoma multiforme cells through downregulation of Bmi-1. Oncol Rep 29: 1805-1810, 2013.
71. Xuan HQ, Xue W, Pan JH, Sha JJ, Dong BJ and Huang YR Downregulation of miR-221,-30d, and-15a contributes to pathogenesis of prostate cancer by targeting Bmi-1. Biochemistry (Mosc). 80: 276-283, 2015.

72. Guo JL, Li WP, Shi HL, Xie XH, Li LS, Tang HL, Wu MQ, Kong Y, Yang L, Gao J, et al: Synergistic effects of curcumin with emodin against the proliferation and invasion of breast cancer cells through upregulation of miR-34a. Mol Cell Biochem 382: 103-111, 2013.

73. Lin SL, Chang DC, Ying SY, Leu D and Wu DTS: MicroRNA miR-302 inhibits the tumorigenecity of human pluripotent stem cells by coordinate suppression of the CDK2 and CDK4/6 cell cycle pathways. Cancer Res 70: 9473-9482, 2010.

74. Li TT, Jian XY, He H, Lai QH, Li XZ, Deng DL, Liu TF, Zhu JH, Jiao HL, Ye YP, et al: MiR-452 promotes an aggressive colorectal cancer phenotype by regulating a Wnt $/ \beta$-catenin positive feedback loop. J Exp Clin Cancer Res 37: 238, 2018.

75. Liu LP, Chen K, Wu JH, Shi L, Hu B, Cheng SY, Li MF and Song LB: Downregulation of miR-452 promotes stem-like traits and tumorigenicity of gliomas. Clin Cancer Res 19: 3429-3438, 2013.

76. Li X, Song Y, Liu D, Zhao J, Xu J, Ren J, Hu Y, Wang Z, Hou Y and Zhao G: MiR-495 promotes senescence of mesenchymal stem cells by targeting Bmi-1. Cell Physiol Biochem 42: 780-796, 2017. International (CC BY-NC-ND 4.0) License. 